\title{
Smart Wheelchair with Dual Control Using Touchpad and Android Mobile Device
}

\author{
Yna Victoria P. Paulite, Neil Jerome C. Carandang, Edwin R. Arboleda* \\ Department of Computer and Electronics Engineering, College of Engineering and Information Technology, \\ Cavite State University, Indang, Cavite, Philippines
}

\begin{tabular}{l} 
Article Info \\
\hline Article history: \\
Received Nov 9, 2018 \\
Revised Jan 31, 2018 \\
Accepted Feb 15, 2018 \\
\hline Keyword: \\
Android app \\
C programming language \\
Electronic wheelchair \\
Gizduino AtMega644 \\
Touch pad
\end{tabular}

Article Info

Article history

Received Nov 9, 2018

Revised Jan 31, 2018

Accepted Feb 15, 2018

\begin{abstract}
The general objective of the design was to develop a touchpad controlled Android-based electronic wheelchair. It aimed to construct the Androidbased circuitry and program for the path finding mechanism of the drive system and interface the Arduino-based circuit to the electronic wheelchair setup. It was designed to evaluate the system in terms of the speed of the electronic wheelchair, reliability of the sensors to avoid obstacle, and ease of use of the wheelchair. C Programming Language was used by the system to control and manipulate the microcontroller, Gizduino AtMega644. The Android application was programmed using the Java Language and Eclipse as the IDE. Its ports were used to interface input and output devices such as the ultrasonic sensors, infrared proximity sensor, touchpad, Bluetooth module, motor and motor driver. There was a satisfactory rating for the evaluation of the system while the Android software was rated excellent as a navigational controller.
\end{abstract}

Copyright (C) 2018 Institute of Advanced Engineering and Science. All rights reserved.

\section{Corresponding Author:}

Edwin R. Arboleda,

Department of Computer and Electronics Engineering,

College of Engineering and Information Technology, Cavite State University,

Indang, Cavite, Philippines.

Email: edwin.r.arboleda@cvsu.edu.ph

\section{INTRODUCTION}

Technology is the present world. It affects people's daily lives. A list of the benefits of technology would be very long indeed and this includes the medical field [1]. This wheelchair project offers people with disabilities [2-3], people who with various degrees of paralysis [4] a chance to navigate. The degree of the paralysis must only be limited either from the lower body, the upper body, except from the fingers, the wrist and the hand [5-6]. Otherwise, the person cannot control it.

The person uses a touchpad to maneuver the wheelchair independently [7-8]. On the other hand, the helper can remotely control the wheelchair via smart phone, using an application that is powered by the Android Operating System. The wheelchair is also equipped with sensors [9-10]. It can maneuver through incoming walls, people, stairs, or any obstacle that it comes in close contact with [11]. When detected, the wheelchair automatically selects the best path to the selected course.

Romero et al. [12] presented the design, implementation and experimental platform of a low-cost intelligent wheelchair for the motor-disabled. A cheaper electric power wheelchair, which cost one third of the commercial ones was the first prototype developed. The said prototype can do both manual and autonomous operations. Manual types depend on a joystick and are made for people that have the capability of controlling the wheelchair despite their disability. Autonomous operation on the other hand leans on a mobile robotics inspired computer vision system used to navigate through corridors, halls, indoors/outdoors, 
among other structured environments. It is purposely devised for severely impaired persons, such as tetraplegics.

The development of autonomous mobile robot systems has become a current interest in the area of artificial intelligence. Autonomous robots are attracting more attention all over the world due to the recent improvements in technology. In both industry and academia, there are research and development activities that are now ongoing. For obstacles' positions that are uncertain, path finding for robots in complex ground environment is being searched. Consequently, a new path finding method integrating line tracking and obstacle avoidance algorithms is proposed and implemented according to $\mathrm{Wu}$ et al. [13]. He presented the design and implementation of a multi-sensor based path finding autonomous exploration robot system, 2RE, with the VEX robotics design system. The robot system with the new path finding algorithm can effectively solve path finding problem in complex ground environment and it avoid collision with the obstacles as shown on the results of the project [14].

The design and realization of the mobile application for the Android operating system is focused on manual control of mobile robot using wireless Bluetooth technology [15-16]. The application allows the robot control interaction with the display, or voice. When graphical interface is used, the current distance of the robot from obstacles can be monitored [17]. The measurement of distance is carried out by ultrasonic sensor placed in front of the robot. It is necessary to build a prototype of a mobile robot for the development of the application. The prototype of the mobile robot is based on the differential gear.

A mobile robot system suitable for performing various tasks for the physically disabled has been then developed. The mobile robot uses ultrasonic range finders for detection and mapping in order to prevent collision with various obstacles [18]. An obstacle avoidance strategy used for this robot relies vitaly on the performance of the ultrasonic range finders although the sensors have limitations on the obstacle avoidance algorithm [19-20].

In reference to the current innovations mentioned above, this paper presents the design and implementation of a touchpad controlled android-based path finding automated wheelchair intended for physically disabled people. It primarily focuses on the avoidance of obstacles through sensors and the distance the wheelchair had travelled as indicated by the Android application used.

\section{RESEARCH METHOD}

\subsection{Design Considerations}

The materials used for this study are available in the local market and not more expensive than that of the commercially available electronic wheelchairs. The materials that were used in the project are the following: the manual wheelchair is a standard wheelchair that weighs $20 \mathrm{~kg}$ and capable of carrying a maximum load of $120 \mathrm{~kg}$. The wiper motors that were used were second hand because a new one would be very costly and hard to find. The motor drivers, the sensors, the microcontrollers, and the modules that were used for the main circuit are available at electronic shops and hobby shops locally. There was a lot to consider for the modification of the manual wheelchair. The following were taken into consideration: the size and position of the sprocket and chain ring for maximum efficiency; the extension of the axle; and the placement and weight of the battery. As for the main circuit, it was taken into account that it must not be easily removed and must be protected from dust and the weather.

\subsection{Selection of Motor and Motor Driver}

A DC motor with permanent magnet connected field [21] was used since the application range of this motor includes the electric wheelchair because of its high torque and power density [22-23]. A windshield wiper motor which uses permanent magnet field was applied in the design. The Toyota wiper motor used has an output rating of $50 \mathrm{~W}$ and has a load current of $4 \mathrm{~A}-6.5 \mathrm{~A}$ from a weight range of 40 to $90 \mathrm{~kg}$. Additionally, to allow the motors to run forward and backward (reverse), an H-bridge electronic circuit was utilized. The H-bridge was designed depending on the current rating of the battery that will not limit the maximum operation of the wiper motors.

\subsection{Selection of Battery}

One $12 \mathrm{Ah} 12 \mathrm{~V}$ battery was used. It has a weight of $7 \mathrm{~kg}$. It was estimated that an average of $1 \mathrm{~A}$ is consumed in every hour of use of the entire system. Thus, the 12 Ah battery is compatible for 10-12 hours of use. It is a type of lead acid battery used for cars and motorcycles. It was used since it is intended to provide a steady amount of current over a long period of time and can withstand being deeply discharged over and over again. 


\subsection{Design and Construction of a Navigational Controller Circuit}

The design focused on users who can operate the electronic wheelchair using their hands. A capacitive touchpad was used because it is similar to Android-based phones that use capacitive touch panel [24]. It is also easy to use.

\subsection{Interfacing the Navigational Controller and Sensors, and Bluetooth Module to the Arduino} Circuit

Figure 1 shows the block diagram of the Android-based electronic wheelchair [25]. The navigation controller pins, sensors, and Bluetooth module were all connected to the microcontroller.

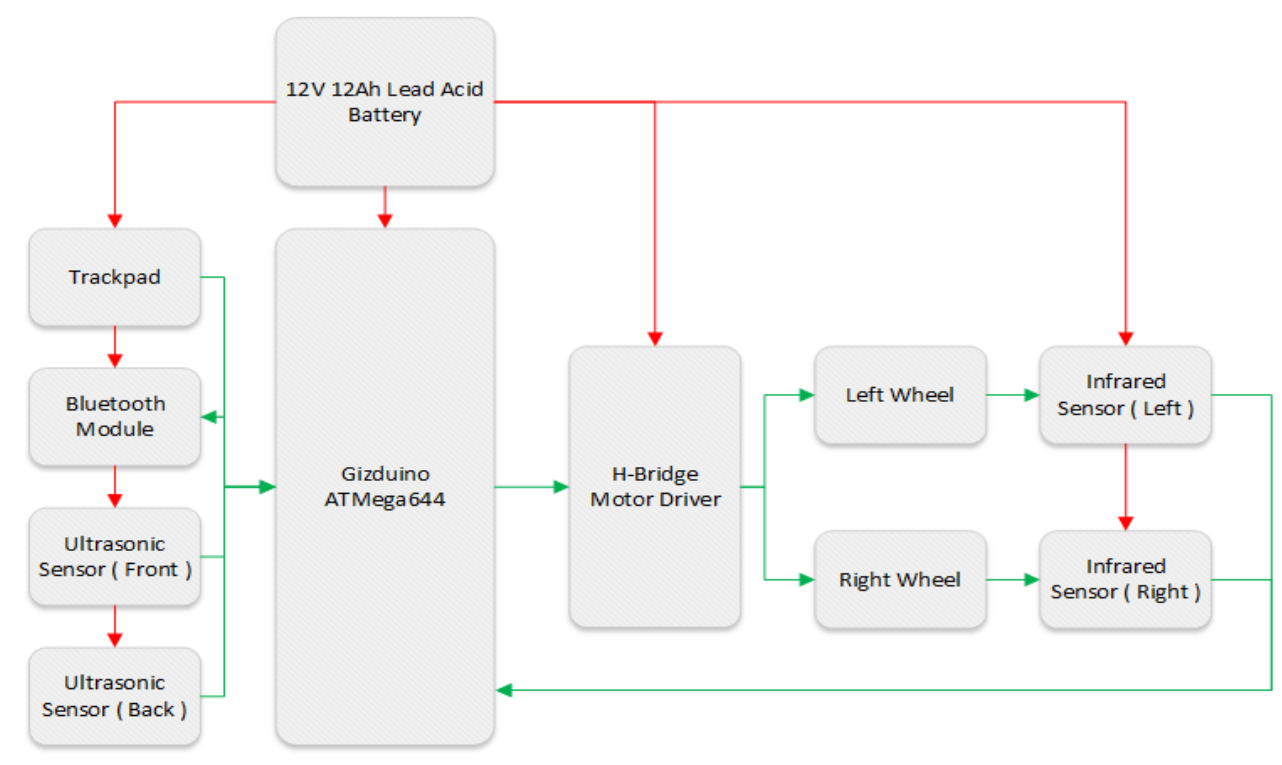

Figure 1. The block diagram of smart wheelchair with dual control using touchpad and android app

\subsection{Modification of the Manual Wheelchair}

The following materials or components were installed on the manual wheelchair: two wiper motors, battery, battery, capacitive touchpad, two ultrasonic sensors, three IR sensors, and the main circuit. Figure 2 shows the modified manual wheelchair.

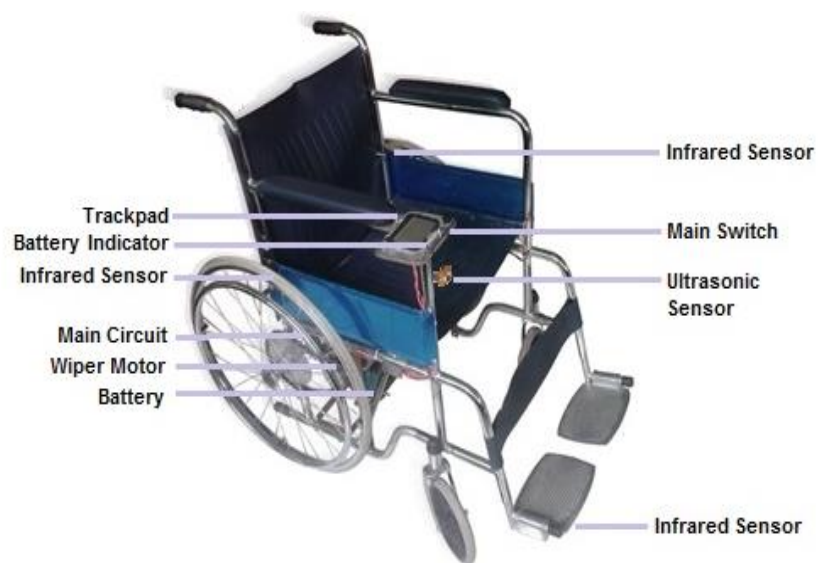

Figure 2. The modified electronic wheelchair 


\subsection{Software Development for the Electronic Wheelchair}

The software that was used for the programming of the system is C Programming Language and was uploaded to the AtMega644 Arduino.

\subsection{Developing the Software for the Android-Based Device}

The Android application was programmed using the Java language and Eclipse as the IDE. The application was not created by the proponents themselves. The Android application created and developed by the proponents of the design project "Design and Development of Android Based Path Finding Mobile Robot" was the same application used in this design project. The name of the application is Aprobot. The application was just modified to become compatible with higher Android versions. The application is an input device that will serve as an interface for the navigation controller, and auto pathfinder. Figu re 3 shows the Aprobot android apps.

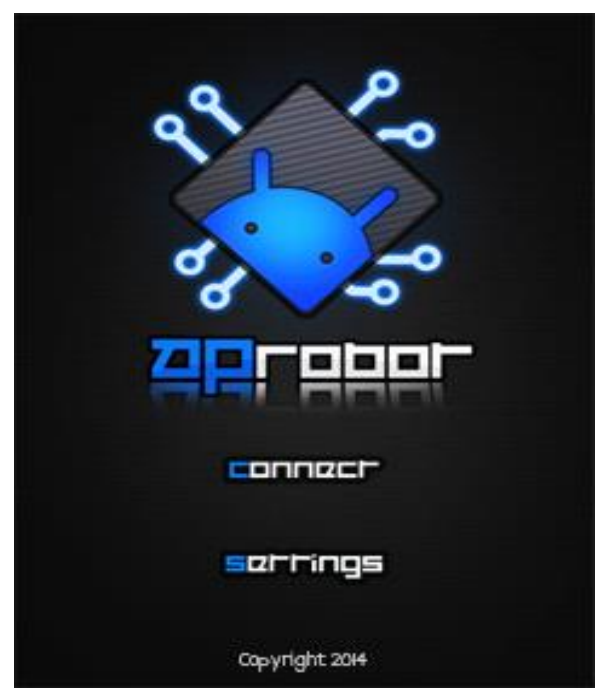

Figure 3. The Android application interface

\subsection{Testing and Evaluation}

For technical evaluation, the electronic wheelchair was tested in different distances several times per mode of operation. The capability of the transmission was recorded since it uses a Bluetooth connection to connect the Android application to the wheelchair. The maximum weight that the wheelchair could carry was also recorded. Figure 4 show the actual testing of the developed wheelchair wherein it is controlled from a distance by the Aprobot Android apps.

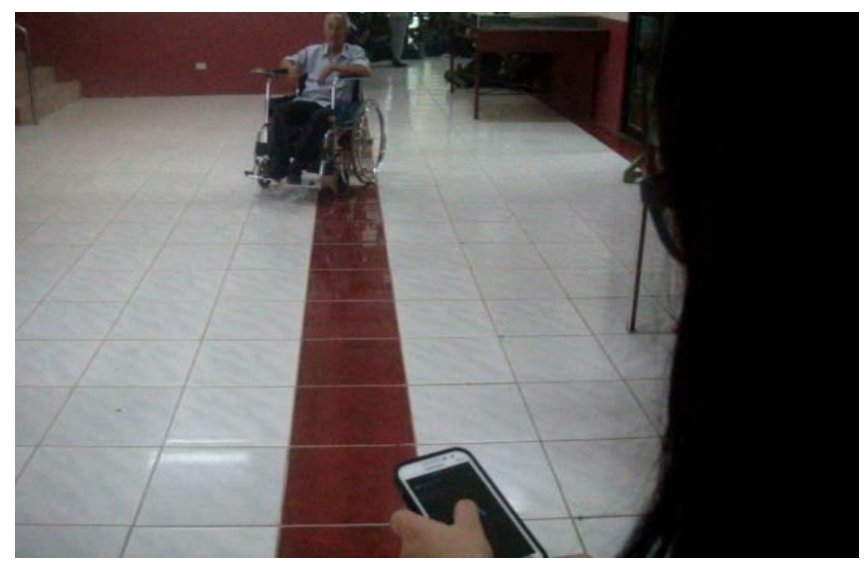

Figure 4. Using an android mobile device to remotely control the electronic wheelchair 
For the user evaluation test, 30 people tested the device. Among these were Cavite State Univers ity students and two PWDs. The students were categorized into four weight ranges: $40-56 \mathrm{~kg}, 57-73 \mathrm{~kg}$, and 74$90 \mathrm{~kg}$. The authors set marks from $1 \mathrm{~m}$ to $10 \mathrm{~m}$ to measure the time travelled of every respondent. The speed was computed by dividing the distance travelled by the total time travelled in seconds. The proponents prepared a survey questionnaire to examine the user's perception about the specific functions of the Android based touchpad controlled electronic wheelchair. Five questions were prepared to evaluate the touchpad controlled android based electronic wheelchair, namely: (1) the touchpad controller is easy to use; (2) the Android software is easy to use; (3) the sensors work properly; (4) the path finding system works properly; (5) and the electronic wheelchair is easy to use. Each question was rated on how the respondents find the electronic wheelchair efficient and user-friendly using Table 1 as reference.

Table 1. Reference for Rating the Accuracy of the Project

\begin{tabular}{cl}
\hline RATING & \multicolumn{1}{c}{ DESCRIPTION } \\
\hline 5 & Excellent - Exceeds the expected function of the project \\
4 & Satisfactory - Meet all the functions of the project \\
3 & Fair - Good enough for its use \\
2 & Needs improvement - Did not meet all the functions of the project \\
1 & Poor - Not effective and efficient \\
\hline
\end{tabular}

Table 2 shows the mean range weight interpretation of the Likert scale used in the survey questionnaires

Table 2. Mean Range Weight Interpretation

\begin{tabular}{cl}
\hline RANGE & \multicolumn{1}{c}{ DESCRIPTION } \\
\hline $4.50-5.00$ & $5-$ Excellent \\
$3.50-4.49$ & $4-$ Satisfactory \\
$2.50-3.49$ & 3 - Fair \\
$1.50-2.49$ & 2 - Needs Improvement \\
$1.00-1.49$ & 1 - Poor \\
\hline
\end{tabular}

During the testing and evaluation period, the authors recorded the measurements made from the wheelchair and the participants were given an evaluation form to rate the effectiveness of the electronic wheelchair operation.

\section{RESULTS AND ANALYSIS}

\subsection{Principle of Operation}

The electronic wheelchair was designed to provide a mobility device for people with disabilities. The design project consists of the following: wheelchair, touchpad, two ultrasonic sensors, two infrared sensors, two wiper motors, battery, motor drivers, Bluetooth module and Gizduino ATMega644 microcontroller which controls the whole operation of the system.

The electronic wheelchair automatically moves or transports the user to the direction indicated by the user, either touchpad or Android-based controlled. It is supplied by a 12 Ah 12 V lead acid battery. Once the main switch of the electronic wheelchair is switched on, the battery will start to supply power to the main circuit of the system which consists of Gizduino ATMega644, Hybrid Motor Driver, Bluetooth RxTx Module, regulators, and amplifier. The infrared sensors are placed at both sides of the wheelchair near the wheel. It serves as an improvised tachometer by detecting the black marks placed at every 45 degrees on the wheel [26]. The touchpad placed at the right side of the wheelchair or the joystick-mode of the Android application via Bluetooth connection can navigate by tapping the right coordinates for forward, backward, left rotation and right rotation. Upon forward or backward navigation, the $12 \mathrm{~V}$ wiper motors will rotate forward or backward together, respectively. But in the event that the ultrasonic sensor in front of the wheelchair detects that the wheelchair is heading towards an obstacle with distance of $1.2 \mathrm{~m}$ in front and 0.6 $\mathrm{m}$ at the rear, the electronic wheelchair will automatically stop. Upon left and right navigation, the main circuit will only allow the forward movement of the right and left motor, respectively. While, the left and right wheels will remain stationary respectively, this makes the wheelchair move going to the left and to the right. The electronic wheelchair has also an additional feature of path finding. This works through Android application via Bluetooth. The settings of the application are configured from joystick mode to auto-path 
mode by creating a map. One tile in the map is equivalent to $0.304 \mathrm{~m}$ by $0.304 \mathrm{~m}$. The starting point is set by long pressing a tile of choice then another tile is tapped for the destination point. It is important to take note that the map is always due north of the wheelchair. The wheelchair will automatically find its way from the starting point to the destination point and avoid obstacles along the way.

\subsection{User-Acceptance Data Analysis}

Table 3 presents the data gathered from the 28 Cavite State University students. It shows the time each respondent travelled using Android software and auto-path finding system with different routes in $10 \mathrm{~m}$. Their speed using different modes of operation were computed and recorded. It also shows that the weight of the user affects the speed of the electronic wheelchair. Heavier users moved slower in all modes of operation.

Table 3. Speed of Electronic Wheelchair at $10 \mathrm{~m}$ (Cavite State University students)

\begin{tabular}{|c|c|c|c|c|c|c|}
\hline $\begin{array}{l}\text { WEIGHT } \\
(\mathrm{kg})\end{array}$ & $\begin{array}{c}\text { TIME } \\
\text { TRAVELLED (s) } \\
\text { Android Software }\end{array}$ & $\begin{array}{c}\text { TIME } \\
\text { TRAVELLED (s) } \\
\text { Auto-Path } \\
\text { (Route 1) }\end{array}$ & $\begin{array}{c}\text { TIME } \\
\text { TRAVELLED (s) } \\
\text { Auto-Path } \\
\text { (Route 2) }\end{array}$ & $\begin{array}{l}\text { SPEED } \\
(\mathrm{m} / \mathrm{s}) \\
\text { Android } \\
\text { Software }\end{array}$ & $\begin{array}{l}\text { SPEED } \\
(\mathrm{m} / \mathrm{s}) \\
\text { Auto-Path } \\
\text { (Route 1) }\end{array}$ & $\begin{array}{c}\text { SPEED } \\
(\mathrm{m} / \mathrm{s}) \\
\text { Auto-Path } \\
\text { (Route 2) }\end{array}$ \\
\hline 40 & 48 & 42 & 46 & 0.21 & 0.24 & 0.22 \\
\hline 45 & 68 & 50 & 56 & 0.15 & 0.20 & 0.18 \\
\hline 45 & 63 & 48 & 53 & 0.16 & 0.21 & 0.19 \\
\hline 45 & 73 & 51 & 55 & 0.14 & 0.20 & 0.18 \\
\hline 45 & 61 & 48 & 56 & 0.16 & 0.21 & 0.18 \\
\hline 46 & 69 & 49 & 55 & 0.15 & 0.20 & 0.18 \\
\hline 47 & 67 & 49 & 57 & 0.15 & 0.20 & 0.18 \\
\hline 47 & 80 & 51 & 57 & 0.13 & 0.20 & 0.19 \\
\hline 48 & 83 & 53 & 59 & 0.12 & 0.19 & 0.17 \\
\hline 48 & 76 & 53 & 58 & 0.13 & 0.19 & 0.17 \\
\hline 48 & 86 & 51 & 58 & 0.12 & 0.20 & 0.17 \\
\hline 48 & 58 & 52 & 57 & 0.17 & 0.19 & 0.18 \\
\hline 48 & 71 & 51 & 59 & 0.14 & 0.20 & 0.17 \\
\hline 49 & 108 & 53 & 58 & 0.09 & 0.19 & 0.17 \\
\hline 49 & 68 & 54 & 60 & 0.15 & 0.19 & 017 \\
\hline 49 & 66 & 54 & 61 & 0.15 & 0.19 & 0.16 \\
\hline 49 & 52 & 52 & 60 & 0.19 & 0.19 & 0.17 \\
\hline 50 & 66 & 54 & 62 & 0.15 & 0.19 & 0.16 \\
\hline 51 & 68 & 55 & 60 & 0.15 & 0.18 & 0.17 \\
\hline 52 & 116 & 57 & 63 & 0.09 & 018 & 0.16 \\
\hline 55 & 103 & 56 & 64 & 0.10 & 0.19 & 0.16 \\
\hline 55 & 60 & 57 & 63 & 0.17 & 0.18 & 0.16 \\
\hline 55 & 82 & 57 & 65 & 0.12 & 0.18 & 0.15 \\
\hline 61 & 47 & 59 & 65 & 0.21 & 0.17 & 0.15 \\
\hline 67 & 119 & 63 & 68 & 0.08 & 0.16 & 0.15 \\
\hline 75 & 117 & 69 & 73 & 0.09 & 0.14 & 0.14 \\
\hline 75 & 137 & 68 & 75 & 0.07 & 0.15 & 0.13 \\
\hline 90 & 123 & 79 & 83 & 0.08 & 0.13 & 0.12 \\
\hline
\end{tabular}

Table 4 presents the data gathered from two persons with disabilities. It shows the time each PWD travelled using Android software and auto-path finding system with different routes in $10 \mathrm{~m}$. Their speeds using different modes of operation were computed and recorded. It also shows that the weight of the user affects the speed of the electronic wheelchair.

Table 4. Speed of Electronic Wheelchair at $10 \mathrm{~m}$ (PWDs)

\begin{tabular}{|c|c|c|c|c|c|c|c|}
\hline & $\begin{array}{c}\text { WEIGHT } \\
(\mathrm{kg})\end{array}$ & $\begin{array}{c}\text { TIME } \\
\text { TRAVELLED } \\
\text { (s) } \\
\text { Android } \\
\text { Software }\end{array}$ & $\begin{array}{c}\text { TIME } \\
\text { TRAVELLED } \\
\text { (s) } \\
\text { Auto-Path } \\
\text { (Route 1) }\end{array}$ & $\begin{array}{c}\text { TIME } \\
\text { TRAVELLED } \\
\text { (s) } \\
\text { Auto-Path } \\
\text { (Route 2) }\end{array}$ & $\begin{array}{l}\text { SPEED } \\
(\mathrm{m} / \mathrm{s}) \\
\text { Android } \\
\text { Software }\end{array}$ & $\begin{array}{c}\text { SPEED } \\
(\mathrm{m} / \mathrm{s}) \\
\text { Auto-Path } \\
\text { (Route 1) }\end{array}$ & $\begin{array}{c}\text { SPEED } \\
(\mathrm{m} / \mathrm{s}) \\
\text { Auto-Path } \\
\text { (Route 2) }\end{array}$ \\
\hline PWD 1 & 50 & 60 & 55 & 63 & 0.17 & 0.18 & 0.16 \\
\hline PWD 2 & 72 & 90 & 67 & 74 & 0.11 & 0.15 & 0.14 \\
\hline
\end{tabular}

\subsubsection{Question 1. The touchpad controller is easy to use.}

The mean of the ratings given by the respondents is shown in Table 5. There was a little difference in the answers of the respondents belonging to the three weight ranges, but the data computed still showed high rating for ease of use of the touchpad controller. 
Table 5. Data Gathered by Weight Range for Question No. 1

\begin{tabular}{ccccc}
\hline $\begin{array}{c}\text { WEIGHT RANGE } \\
(\mathrm{kg})\end{array}$ & $\begin{array}{c}\text { AVERAGE TIME } \\
(\mathrm{s})\end{array}$ & $\begin{array}{c}\text { AVERAGE SPEED } \\
(\mathrm{m} / \mathrm{s})\end{array}$ & MEAN & $\begin{array}{c}\text { PERCENTAGE } \\
\%\end{array}$ \\
\hline $40-56$ & 70.41 & 0.15 & 4.00 & 80.00 \\
$57-73$ & 79.29 & 0.13 & 4.33 & 86.67 \\
$74-90$ & 83.00 & 0.15 & 4.33 & 86.67 \\
\hline
\end{tabular}

\subsubsection{Question 2. The Android software is easy to use.}

The mean of the ratings given by the respondents is shown in Table 6. There was a little difference in the answers of the respondents belonging to the three weight ranges, but the mean computed still showed high rating for ease of use of the Android software.

Table 6. Data Gathered by Weight Range for Question No. 2

\begin{tabular}{ccccc}
\hline $\begin{array}{c}\text { WEIGHT RANGE } \\
(\mathrm{kg})\end{array}$ & $\begin{array}{c}\text { AVERAGE TIME } \\
(\mathrm{s})\end{array}$ & $\begin{array}{c}\text { AVERAGE SPEED } \\
(\mathrm{m} / \mathrm{s})\end{array}$ & MEAN & $\begin{array}{c}\text { PERCENT AGE } \\
\%\end{array}$ \\
\hline $40-56$ & 70.41 & 0.15 & 4.79 & 95.83 \\
$57-73$ & 79.29 & 0.13 & 4.33 & 86.67 \\
$74-90$ & 83.00 & 0.15 & 5.00 & 100.00 \\
\hline
\end{tabular}

\subsubsection{Question 3. The sensors work properly.}

The mean of the ratings given by the respondents is shown in Table 7. There was a little difference in the answers of the respondents belonging to the three weight ranges, but the mean computed still showed high rating for the reliability of the sensors. During the technical evaluation, the reliability of the sensors was further tested.

Table 7. Data Gathered by Weight Range for Question No. 3

\begin{tabular}{ccccc}
\hline $\begin{array}{c}\text { WEIGHT RANGE } \\
(\mathrm{kg})\end{array}$ & $\begin{array}{c}\text { AVERAGE TIME } \\
(\mathrm{s})\end{array}$ & $\begin{array}{c}\text { AVERAGE SPEED } \\
(\mathrm{m} / \mathrm{s})\end{array}$ & MEAN & $\begin{array}{c}\text { PERCENT AGE } \\
\%\end{array}$ \\
\hline $40-56$ & 70.41 & 0.15 & 4.21 & 84.17 \\
$57-73$ & 79.29 & 0.13 & 5.00 & 100.00 \\
$74-90$ & 83.00 & 0.15 & 5.00 & 100.00 \\
\hline
\end{tabular}

\subsubsection{Question 4. The path finding system works properly.}

The mean of the ratings given by the respondents is shown in Table 8 . There was a little difference in the answers of the respondents belonging to the three weight ranges, but the mean computed still showed high rating for reliability of the path finding system.

Table 8. Data Gathered by Weight Range for Question No. 4

\begin{tabular}{ccccc}
\hline $\begin{array}{c}\text { WEIGHT RANGE } \\
(\mathrm{kg})\end{array}$ & $\begin{array}{c}\text { AVERAGE TIME } \\
(\mathrm{s})\end{array}$ & $\begin{array}{c}\text { AVERAGE SPEED } \\
(\mathrm{m} / \mathrm{s})\end{array}$ & MEAN & $\begin{array}{c}\text { PERCENTAGE } \\
\%\end{array}$ \\
\hline $40-56$ & 70.41 & 0.15 & 3.96 & 79.17 \\
$57-73$ & 79.29 & 0.13 & 4.00 & 80.00 \\
$74-90$ & 83 & 0.15 & 3.67 & 73.34 \\
\hline
\end{tabular}

\subsubsection{Question 5. The electronic wheelchair is easy to use.}

The mean of the ratings given by the respondents is shown in Table 9. There was a little difference in the answers of the respondents belonging to the three weight ranges, but the mean computed still showed high rating for the ease of use of the electronic wheelchair.

Table 9. Data Gathered by Weight Range for Question No. 5

\begin{tabular}{ccccc}
\hline $\begin{array}{c}\text { WEIGHT RANGE } \\
(\mathrm{kg})\end{array}$ & $\begin{array}{c}\text { AVERAGE TIME } \\
(\mathrm{s})\end{array}$ & $\begin{array}{c}\text { AVERAGE SPEED } \\
(\mathrm{m} / \mathrm{s})\end{array}$ & MEAN & $\begin{array}{c}\text { PERCENT AGE } \\
\%\end{array}$ \\
\hline $40-56$ & 70.41 & 0.15 & 4.38 & 87.50 \\
$57-73$ & 79.29 & 0.13 & 4.67 & 93.34 \\
$74-90$ & 83.00 & 0.15 & 4.67 & 93.34 \\
\hline
\end{tabular}

IJEEI, Vol. 6, No. 1, March $2018: 86-96$ 
Table 10 shows the average rating of the questions in the user evaluation for the 28 Cavite State University students. The mean was computed per question which corresponded to specific performance level. The ease of use of the Android software was rated excellent while the ease of use of the touchpad controller and the electronic wheelchair, and the reliability of the sensors and path finding system were rated satisfactory.

Table 10. Response on the Performance of the Electronic Wheelchair

\begin{tabular}{|c|c|c|}
\hline QUESTION & MEAN & PERFORMANCE \\
\hline $\begin{array}{l}\text { 1. The touchpad controller is easy to } \\
\text { use. }\end{array}$ & 4.07 & Satisfactory \\
\hline 2. The Android software is easy to use. & 4.77 & Excellent \\
\hline 3. The sensors work properly. & 4.47 & Satisfactory \\
\hline $\begin{array}{l}\text { 4. The path finding system works } \\
\text { properly. }\end{array}$ & 3.93 & Satisfactory \\
\hline $\begin{array}{l}\text { 5. The electronic wheelchair is easy to } \\
\text { use. }\end{array}$ & 4.43 & Satisfactory \\
\hline Total Average & 4.33 & Satisfactory \\
\hline
\end{tabular}

Overall, the performance of the developed electronic wheelchair was rated satisfactory.

Table 11 shows the average time travelled by a certain range of weight at a 25 by 25 tile map with no-obstacle-straight path. Since the respondents weighed from 40 to $90 \mathrm{~kg}$, the ranges set had a $16 \mathrm{~kg}$ weight interval. The wheelchair travelled only 23 tiles in a 25 by 25 map since it occupied 2 tiles. A tile is equivalent to $0.3048 \mathrm{~m}$, thus 23 tiles is equivalent to $7.0104 \mathrm{~m}$. The average speed computed was significant with respect to weight. The effectiveness was based on the evaluation given by the respondents.

Table 12 shows the average time travelled by a certain range of weight at a 25 by 25 tile map with obstacle route. Since the respondents weighed from 40 to $90 \mathrm{~kg}$, the ranges set had a $16 \mathrm{~kg}$ weight in terval. A tile is equivalent to $0.3048 \mathrm{~m}$, thus 23 tiles is equivalent to $7.0104 \mathrm{~m}$. The distance set was also 23 tiles in a 25 by 25 map even with obstacle. This was made to compare the average speed in a straight line from with obstacle. The average speed computed was significant with respect to weight. The effectiveness was based on the evaluation given by the respondents.

Table 11. Speed of Electronic Wheelchair Via Auto-path Finding at 25 x 25 tile map (no obstacle)

\begin{tabular}{cccc}
\hline WEIGHT & $\begin{array}{c}\text { AVERAGE TIME } \\
\text { TRAVELLED }\end{array}$ & $\begin{array}{c}\text { AVERAGE } \\
\text { SPEED }\end{array}$ & EFFECTIVENESS \\
$(\mathrm{kg})$ & $(\mathrm{s})$ & $(\mathrm{m} / \mathrm{s})$ & $(\%)$ \\
\hline $40-56$ & 48.50 & 0.19 & 86.66 \\
$57-73$ & 63.00 & 0.16 & 100.00 \\
$74-90$ & 72.00 & 0.14 & 100.00 \\
\hline
\end{tabular}

Table 12. Speed of Electronic Wheelchair Via Auto-path Finding at 25 x 25 tile map (with obstacle)

\begin{tabular}{cccc}
\hline WEIGHT & $\begin{array}{c}\text { AVERAGE TIME } \\
\text { TRAVELLED }\end{array}$ & $\begin{array}{c}\text { AVERAGE } \\
\text { SPEED }\end{array}$ & EFFECTIVENESS \\
$(\mathrm{kg})$ & $(\mathrm{s})$ & $(\mathrm{m} / \mathrm{s})$ & $(\%)$ \\
\hline $40-56$ & 58.54 & 0.17 & 86.66 \\
$57-73$ & 69.00 & 0.16 & 100.00 \\
$74-90$ & 77.00 & 0.13 & 100.00 \\
\hline
\end{tabular}

Table 13 shows the rating given by the two PWDs invited by the proponents. The average ratings of the PWD were interpreted using the Likert scale. The ease of use of the touchpad controller, Android software and electronic wheelchair were rated excellent. The sensors and the path finding system was rated satisfactory.

Table 13. PWDs User-Acceptance Ratings

\begin{tabular}{cccccc}
\hline $\begin{array}{c}\text { Question } \\
\text { No. }\end{array}$ & 1 & 2 & RATING & 4 & 5 \\
\hline PWD 1 & 4 & 5 & 3 & 3 & 4 \\
PWD 2 & 5 & 4 & 5 & 4 & 5 \\
Average & 4.5 & 4.5 & 4 & 3.5 & 4.5 \\
\hline
\end{tabular}




\subsection{Technical Evaluation Data Analysis}

Table 14 shows the results of the evaluation of the Android application via Bluetooth in different distances. At $3 \mathrm{~m}$, the Android app successfully transmitted the commands to the electronic wheelchair. The expected function of the wheelchair was achieved for three trials. At $6 \mathrm{~m}$, the Android application successfully transmitted the commands to the electronic wheelchair. The expected function of the wheelchair was achieved for three trials. At $9 \mathrm{~m}$, the Android application successfully transmitted the commands to the electronic wheelchair. The expected function of the wheelchair was achieved for three trials. At $12 \mathrm{~m}$, the Android application successfully transmitted the commands to the electronic wheelchair. The wheelchair responded slowly compared to smaller distances. At $15 \mathrm{~m}$, no command was transmitted to the microcontroller, the electronic wheelchair did not respond to any command. The actual range of efficiency of a Bluetooth module is about $12 \mathrm{~m}$, therefore it is set that the effective distance of the wheelchair away from the Android phone was $12 \mathrm{~m}$.

Table 14. Effectiveness Ratio of Android Application Via Bluetooth

\begin{tabular}{ccccc}
\hline $\begin{array}{c}\text { DIST ANCE } \\
(\mathrm{m})\end{array}$ & 1 & TRIAL & 3 & $\begin{array}{c}\text { EFFECTIVENESS } \\
(\%)\end{array}$ \\
\hline 3 & 5 & 5 & 5 & 100.00 \\
6 & 5 & 5 & 5 & 100.00 \\
9 & 5 & 5 & 5 & 100.00 \\
12 & 3 & 5 & 3 & 73.33 \\
15 & 1 & 1 & 1 & 20.00 \\
\hline
\end{tabular}

A technical evaluation was conducted for the reliability of ultrasonic sensors. Three trials for each ultrasonic sens or were conducted. These trials have different obs tacles.

Table 15 shows the effectiveness of the front ultrasonic sensor. Three trials with three different obstacles were conducted. During the trials the wheelchair was set to move forward until it stops during obstacle-detection, then the distance from the ultrasonic sens or to the obstacle was recorded. The data shows that from trial 1 to trial to 3 , the distance ranges from $111-123 \mathrm{~cm}$. The average distance that the front ultrasonic sensor could detect is $122.67 \mathrm{~cm}$ or $1.2 \mathrm{~m}$.

Table 15. Effectiveness Ratio of Front Ultrasonic Sensor

\begin{tabular}{ccc}
\hline TRIAL & OBST ACLE & $\begin{array}{c}\text { DIST ANCE } \\
(\mathrm{cm})\end{array}$ \\
\hline 1 & Person & 123 \\
2 & Wall & 134 \\
3 & Chair & 111 \\
& AVERAGE & 122.67 \\
\hline
\end{tabular}

Table 16 shows the effectiveness of the rear ultrasonic sensor. Three trials with three different obstacles were conducted. During the trials the wheelchair was set to move backward until it stops during obstacle-detection, then the distance from the ultrasonic sensor to the obstacle was recorded. Distance ranged from 52 to $76 \mathrm{~cm}$. The average distance that the front ultrasonic sensor could detect is $60.33 \mathrm{~cm}$ or $0.6 \mathrm{~m}$.

Table 16. Effectiveness Ratio of Rear Ultrasonic Sensor

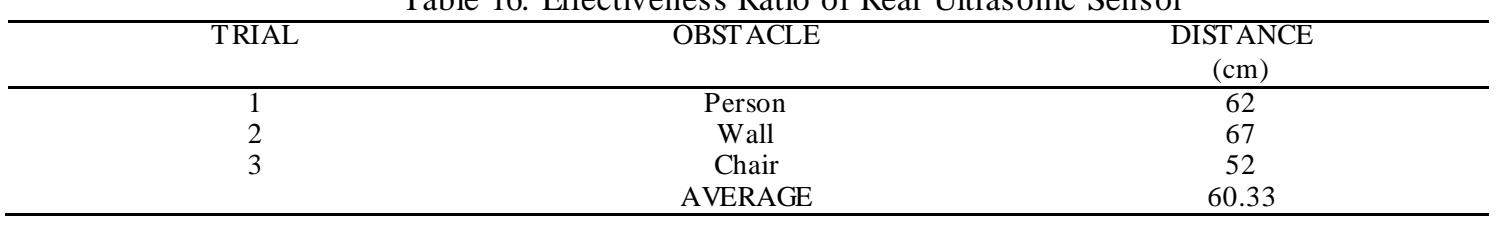

Table 17 shows the effectiveness of infrared sensors for edge detection. Five trials were conducted to show its effectiveness. During the trials the wheelchair was set to move forward to the stairs. The wheelchair stopped when it detected the stairs. The wheelchair was consistent during the five trials conducted. There is 100 percent effectiveness in edge detection. 
Table 17. Effectiveness Ratio of Infrared Sensor for Edge Detection

\begin{tabular}{cccccc}
\hline & & TRIAL & & \\
& 1 & 2 & 3 & 4 & 5 \\
\hline Stop & Yes & Yes & Yes & Yes & Yes \\
\hline
\end{tabular}

A technical evaluation was also conducted for the effectiveness of the path finding system. There were five routes prepared. For each route, there was a path where there were no obstacles present, and a path where there were obstacles present.

Table 18 shows the effectiveness of the path finding system. Five routes were conducted. For each route there is a path where there is no obstacle and a path where there are obstacles present. The weight was held constant since the objective was to make sure that the wheelchair finds the set destination point from the set staring point. The wheelchair successfully completed the route in five different trials. From the data of Table 18, it shows that the time it takes for the wheelchair to reach its destination point is longer than that with no-obstacle present.

Table 18. Effectiveness of Path Finding System

\begin{tabular}{ccccccc}
\hline ROUTE & \multicolumn{2}{c}{$\begin{array}{c}\text { DIST ANCE } \\
(\mathrm{m})\end{array}$} & $\begin{array}{c}\text { WEIGHT } \\
(\mathrm{kg})\end{array}$ & $\begin{array}{c}\text { SPEED } \\
(\mathrm{m} / \mathrm{s})\end{array}$ & $\begin{array}{c}\text { TIME } \\
(\mathrm{s})\end{array}$ \\
& w/o obstacle & w/ obstacle & & & w/o obstacle & w/ obstacle \\
\hline 1 & 4.27 & 5.49 & 60 & 0.23 & 18 & 24 \\
2 & 4.65 & 5.87 & 60 & 0.23 & 20 & 28 \\
3 & 3.96 & 5.79 & 60 & 0.23 & 15 & 26 \\
4 & 4.65 & 5.87 & 60 & 0.23 & 19 & 27 \\
5 & 4.27 & 6.10 & 60 & 0.23 & 18 & 30 \\
\hline
\end{tabular}

\section{CONCLUSION}

Provide a statement that what is expected, as stated in the "Introduction" chapter can ultimately result in "Results and Discussion" chapter, so there is compatibility. Moreover, it can also be added the prospect of the development of research results and application prospects of further studies into the next (based on result and discussion).

\section{REFERENCES}

[1] L. Herdiman, F. Kusumawardani, S. Susmartini, and I. Pryadhitama, "Manual wheelchair intervention on transmission system by assistive technology to increase user mobility," in 2016 2nd International Conference of Industrial, Mechanical, Electrical, and Chemical Engineering, ICIMECE 2016, 2017, pp. 225-230.

[2] E. R. Arboleda, M. C. T. Alegre, and K. F. Idica, "Development of a Low-Cost Electronic Wheelchair with Obstacle Avoidance Feature," J. Mechatronics, Electr. Power, Veh. Technol., vol. 6, no. 2, p. 89, 2015.

[3] Y. Hirata and Y. Tanaka, "Motion Control of Cycling Wheelchair With Continuously Variable Transmission and Clutch," IEEE Robot. Autom. Lett., vol. 3, no. 1, pp. 148-154, 2018.

[4] M. I. Arzak, U. Sunarya, and S. Hadiyoso, "Design and implementation of wheelchair controller based electroencephalogram signal using microcontroller," Int. J. Electr. Comput. Eng., vol. 6, no. 6, pp. 2878-2886, 2016.

[5] A. Ruíz-Serrano, R. Posada-Gómez, A. M. Sibaja, G. A. Rodríguez, B. E. Gonzalez-Sanchez, and O. O. SandovalGonzalez, "Development of a Dual Control System Applied to a Smart Wheelchair, using Magnetic and Speech Control," in 2013 Iberoamerican Conference on Electronics Engineering and Computer Science Development, 2013, vol. 7, pp. 158-165.

[7] B. Majumder, Apratim; Banerjee, Niladri; Nayak, Shikha; Chakraborty, "Design of an Automatic Path Finding Wheelchair with Intelligent Guidance System," IFSA Publ. S.L., vol. 3, no. Mar, pp. 1-7, 2011.

[8] R. M. R. Kallam and H. kumar Sharma, "Development of Intelligent Power Wheelchair," in 2017 IEEE 7th International Advance Computing Conference Development, 2008, vol. 2006, no. 23, pp. 561-566.

[9] V. L. Valenzuela and V. F. de Lucena, "Remote Monitoring and Control of an Electric Powered Wheelchair in an Assisted Living Environment," in IFAC-PapersOnLine, 2016, vol. 49, no. 30, pp. 181-185.

[10] M. Onishi, S. Shibata, Y. Goto, K. Kobayashi, and K. Watanabe, "Development of Intuitive Visual Navigation Interface for Electric Wheelchair," in SICE Annual Conference 2007, 2007, pp. 2080-2083.

[11] M. Hinderer, P. Friedrich, and B. Wolf, “An autonomous stair-climbing wheelchair,” Rob. Auton. Syst., vol. 94, pp. 219-225, 2017.

[12] B. Romero, A. Camacho, J. Varona, C. Delgado, and R. Velázquez, "A low-cost electric power wheelchair with manual and vision-based control systems, ” in IEEE AFRICON 2009, 2009, no. September, pp. 5-10. 
[13] F. Wu, M. Cabral, and L. Jiang, "Design and Implementation of a Path Finding Autonomous Robot System Using Multiple Sensors," in 2010 International Conference on Computational Intelligence and Software Engineering, 2010, pp. 1-4.

[14] I. Iswanto, O. Wahyunggoro, and A. I. Cahyadi, "Quadrotor Path Planning Based On Modified Fuzzy Cell Decomposition Algorithm," TELKOMNIKA (Telecommunication Comput. Electron. Control., vol. 14, no. 2, pp. 655-664, 2016.

[15] J. Nádvorník and P. Smutný, "Remote control robot using Android mobile device" in Control Conference (ICCC), 2014 15th International Carpathian, 2014, pp. 373-378

[16] R. Shepherd, "Bluetooth wireless technology in the home," Electron. Commun. Eng. J., no. October, pp. 195-203, 2001.

[17] S. Y. Araki et al., "Computational Modelling of an Automatic Wheelchair Lift System for Assistive Technology Description of the Lifting System Study and Computational Simulation of the Lifting Process," in 2017 3rd International Conference on Control, Automation and Robotics Computational, 2017, pp. 448-452.

[18] W. Budiharto, A. Santoso, D. Purwanto, and A. Jazidie, "Multiple Moving Obstacles Avoidance of Service Robot using Stereo Vision,” TELKOMNIKA (Telecommunication Comput. Electron. Control., vol. 9, no. 3, pp. 433-444, 2011.

[19] J. Borenstein and Y. Koren, "Obstacle Avoidance with Ultrasonic Sensors," IEEE J. Robot. Autom., vol. 4, no. 2, pp. 213-218, 1988

[20] C. Wahyufitriy ani, S. Susmartini, and I. Priadythama, "Review of intelligent wheelchair technology control development in the last 12 years,” 2016 2nd Int. Conf. Ind. Mech. Electr. Chem. Eng. ICIMECE 2016, pp. 201206, 2017.

[21] Sang-Hoon Kim, Chapter 1 - Fundamentals of electric motors, In Electric Motor Control, Elsevier, 2017, Pages 137, ISBN 9780128121382, https://doi.org/10.1016/B978-0-12-812138-2.00001-5. (http://www.sciencedirect.com/science/article/pii/B9780128121382000015)

[22] R. Ilka and S. A. Gholamian, "Optimum Design of a Five-phase Permanent Magnet Synchronous Motor for Underwater Vehicles by use of Particle Swarm Optimization," TELKOMNIKA (Telecommunication Comput. Electron. Control., vol. 10, no. 4, pp. 715-724, 2012.

[23] R. G. Shriwastava, M. B. Diagavane, and S. R. Vaishnav, "Literature Review of Permanent Magnet AC Motors Drive for Automotive Application," Bul. Tek. Elektro dan Inform. (Bulletin Electr. Eng. Informatics), vol. 1, no. 1, pp. 7-14, 2012.

[24] K. Mizuhara, H. Hatano, and K. Washio, "The effect of friction on the usability of touchpad," Tribol. Int., vol. 65, pp. 326-335, 2013.

[25] S. Desai, S. S. Mantha, and V. M. Phalle, “Advances in smart wheelchair technology,” in 2017 International Conference on Nascent Technologies in Engineering, ICNTE 2017 - Proceedings, 2017.

[26] S. Nurmaini, S. Zaiton, and R. Firnando, "Cooperative Avoidance Control-based Interval Fuzzy Kohonen Networks Algorithm in Simple Swarm Robots," TELKOMNIKA (Telecommunication Comput. Electron. Control., vol. 12, no. 4, p. 795, 2014

IJEEI, Vol. 6, No. 1, March 2018 : 86 - 96 